\title{
Residential Care Facility
}

National Cancer Institute

\section{Source}

National Cancer Institute. Residential Care Facility. NCI Thesaurus. Code C154427.

A residential group facility for individuals who are able to attend to most of their personal and medical care. Generally, residents receive personal care and meals and have staff available around the clock, but nursing and medical care usually are not provided on site. 